\title{
DOCUMENTO, MEMÓRIA E ARQUIVO NA ARTE CONTEMPORÂNEA: ALGUMAS REFLEXÕES SOBRE A OBRA FOTOGRÁFICA IMEMORIAL DE ROSAGELA RENNÓ.
}

\author{
DOCUMENT, MEMORY AND FILE IN CONTEMPORARY ART: SOME \\ REFLECTIONS ON THE PHOTOGRAPHIC WORK OF IMEMORIAL \\ ROSAGELA RENNÓ
}

Enviado em 04 de setembro de 2015 Aceito em 20 de novembro de 2015

Charles Monteiro ${ }^{1}$

\begin{abstract}
Resumo: Este artigo problematiza as relações entre a fotografia, história e esquecimento na obra Imemorial (1994) de Rosangela Rennó. A artista problematiza através do projeto Arquivo Universal os usos sociais, o estatuto da fotografia e seu arquivamento nas instituições públicas, bem como a possibilidade de se construírem narrativas alternativas sobre a construção da nação a partir delas.
\end{abstract}

Palavras-chave: Fotografia. Memória. Esquecimento. Brasília. Rosangela Rennó.

Abstract: This article discuss the relationship between photography, history and forgetting in Imemorial (1994) work of Rosangela Renno. The artist discusses via Universal Archive project the social uses of the photography and your filing status in public institutions as well as the ability to construct alternative narratives of nation building from them.

Keywords: Photography. Memory. Oblivion. Brasilia. Rosangela Rennó.

O objetivo do artigo é refletir sobre os usos da memória e as práticas sociais do esquecimento a partir da obra Imemorial (1994) da artista brasileira contemporânea Rosangela Rennó. Segundo Costa (2011, p. 78), os processos da arte contemporânea colocam problemas críticos articulados a outros campos do saber como a Teoria da História e a Arqueologia. Esta reflexão interdisciplinar procura problematizar a produção da informação no contexto da cultura de massa contemporânea, bem como os processos de construção da memória e a própria instituição do museu de arte como espaço de constituição, gestão e legitimação de memórias sociais.

\footnotetext{
1 Doutor em História Social (PUC-SP), pós-doutorado em História da Arte (Université Paris 1 - Panthéon Sorbonne), professor do PPG de História e de Letras da PUC-RS, pesquisador em Produtividade em Pesquisa 2 do CNPq , coordenador do Laboratório de Pesquisa em História da Imagem e do Som do PPG de História da PUCRS e do GT Nacional Imagem, Cultura Visual e História da ANPUH-Brasil. E-mail: monteiro@pucrs.br
} 
No século $X X$, o pensamento historiográfico foi levado a um questionamento radical sobre a produção e os usos sociais dos documentos. Para Michel Foucault "o documento não é o feliz instrumento de uma história que seria em si mesma, e de pleno direito, memória: a história é, para uma sociedade, uma certa maneira de dar status e elaboração à massa documental de que ela não se separa" (Arqueologia do saber, 2005, p. 8). Ou seja, não existem documentos per si, mas sim como fruto de uma operação historiográfica que atribui valor e constrói sentidos a partir dos restos ou vestígios da ação do homem no passado. O problema colocado pelo historiador e o recorte da realidade efetuado por ele é que define se um vestígio torna-se documento ou não. Sempre escolhendo dar voz a certos indivíduos e grupos e deixar outros no silêncio (palavra) ou na invisibilidade (imagem).

A história transforma os documentos em monumentos ao isolar, agrupar, interrelacionar e organizar os conjuntos. O documento não é inócuo, nem tampouco neutro. Ele resulta de um artifício, uma roupagem, uma montagem. Foucault propõe a desmontagem crítica do constructo documento-monumento como dispositivo de poder.

Segundo Walter Benjamin (1987), em suas Teses sobre a História, todo documento de civilização é também documento de barbárie, pois a "História" seria esse cortejo de vencedores que avançam deixando os escombros das suas conquistas para trás. Para este autor, nem os mortos estão a salvo quando somente os vitoriosos contam a historia. Por isso, seria necessário escrever a história a contrapelo, escavar os escombros e escutar essas outras vozes que nos falam dos projetos alternativos de sociedade que foram vencidos.

Situando-me nesse horizonte de compreensão, penso a História com uma das formas das sociedades elaborarem a passagem do tempo, ao lado de outras, como: a construção de monumentos, mausoléus, a comemoração de datas cívicas nacionais e locais, a criação de museus, de disciplinas escolares, a preservação e o tombamento de prédios, de bairros e de cidades, bem como de viagens turístico-culturais, documentários, filmes e romances de época. História e memória são duas formas específicas de tomar consciência do tempo e de explicar o passado, onde se mesclam invenção, estranhamento e identidade (LOWENTHAL, 1998, p. 63-201). Às vezes, estas formas de pensar o passado se sobrepõem e se entrecruzam, em outras elas entram em conflito.

Como afirma David Lowenthal (1995, p. xv-xxvii), o acesso a essa "terra estrangeira" dá-se por meio de um conjunto de situações e objetos que estão ao nosso redor no espaço urbano e podem remeter ao passado: prédios, museus, utensílios, fotos, pinturas, leituras, histórias ouvidas, etc. Essa consciência de passado como algo 
distinto do presente é algo recente, contemporâneo e que também tem a sua história (LOWENTHAL, 1995, p. 3-34). A memória é uma das formas de experienciar a passagem do tempo, de se situar em relação a uma cadeia de gerações, ao conhecimento herdado, a uma ruptura, de equilibrar-se sobre as ondulações vivas do tempo (HARTOG, 1996, p. 143-144).

Como se sabe, toda memória é seletiva, pois trabalha com lembranças e esquecimentos, é uma (re)apresentação de experiências passadas (vividas, ouvidas, lidas ou aprendidas) relacionada às questões que o tempo presente coloca. Seu atributo mais imediato é garantir a continuidade do tempo e permitir resistir a alteridade, ao 'tempo que muda', às rupturas que são o destino de toda a vida humana; em suma, ela constitui - eis uma banalidade - um elemento essencial da identidade, da percepção de si e dos outros. Mas essa percepção difere segundo nos situemos na escala do indivíduo, na escala de um grupo social ou mesmo de toda uma nação (ROUSSO, 1996, p. 94-95).

As sociedades e, no interior dessas, os grupos sociais e indivíduos experienciam o tempo de forma particular. Certas sociedades voltam-se para a memória de um "paraíso perdido" perpassadas pela nostalgia e pela saudade de períodos de crescimento e de harmonia social; outras atêm-se ao tempo presente pregando uma espécie de amnésia do passado; outras, ainda, voltam-se para o futuro como que predestinadas a um destino heroico. Em determinados contextos, produzem uma interpretação do passado que corresponde às necessidades do presente de legitimarse e orientar o horizonte de expectativas sociais para o futuro. O que é válido sobretudo para os momentos de nacionalismo exacerbado.

A memória articula-se através de espaços e tempos privilegiados, sobre os quais a "luz" incide com maior intensidade sobre certos sujeitos (nomes), tempos (datas) e lugares (espaços), enquanto outros permanecem na penumbra, numa gaveta mantida cuidadosamente fechada para que de lá não aflorem contradições, incertezas e instabilidade.

A memória não tem necessidade da experiência de uma continuidade cronológica; não que ela não tenha cadeias de ordenamento, mas ela joga com uma justaposição de tempos. Já a história é elaborada de um ponto de vista construtivo e narrativo do passado, constitui-se como uma maneira de trabalhar sobre o conhecimento do passado. A experiência da História é longitudinal, interpreta o passado em perspectiva, e a experiência da memória é vertical, pois coloca o indivíduo ou o grupo em profundidade dentro do acontecimento, permitindo reconstruí-lo desde dentro (HALBWACHS, 1990, p. 80-89). 
A História é um discurso metódico sobre a experiência do tempo passado em relação às questões do presente, embora esteja carregada da subjetividade do historiador e das marcas de seu lugar social e institucional. A história é mais "ampla" que a memória, no sentido que abarca um grande número de memórias individuais e de grupos ao longo de muitas gerações (HALBWACHS, 1990, p. 89). No entanto, ocorrem influências recíprocas entre estas duas formas de elaborar o passado, no sentido em que a História termina por incorporar elementos da memória coletiva em suas interpretações, via "contaminação" pela transmissão oral do conhecimento e pela experiência de vida do historiador (diante da impossibilidade da história tornar-se um discurso totalmente abstrato, científico e racionalizado) e a memória coletiva termina por incorporar e utilizar certos marcos de referência da História (por meio da aprendizagem formal na escola, das interpretações dos acontecimentos do passado vulgarizadas pelos jornais, emissões de rádio e televisão).

A história da memória trabalha nos desvãos e nas margens, nos lugares de silenciamento da memória, nos esquecimentos e nas lacunas, mas também nos excessos. O historiador transforma essas lacunas e esses excessos em materiais de trabalho para uma compreensão mais abrangente e profunda da forma como uma sociedade elabora e pensa sobre o seu passado e sua trajetória no tempo por meio da produção escrita de especialistas da memória (historiadores, arquivistas, diretores de museus) e intelectuais (cronistas, escritores, jornalistas). O historiador é uma espécie de mestre artesão que trabalha sobre o engenho alheio - memórias, documentos, textos, falas e experiências dos sujeitos - buscando compreender e tecer nas suas narrativas essa variedade de fios em uma trama (história), que pretende dar conta da pluralidade de vozes, sujeitos, espaços e temporalidades da experiência de uma sociedade.

A história da memória aborda a historiografia como uma produção consciente e intencional de uma memória social, pois problematiza a escolha e a organização dos sujeitos, espaços e tempos que são dignos de serem rememorados, bem como os meios de organização através dos quais as lembranças são transmitidas e recriadas. ${ }^{2} \mathrm{~A}$ história da memória problematiza a forma como os grupos sociais e as instituições inventam tradições ou se apropriam da memória coletiva, ressignificando-a com fins específicos (HOBSBAWN; RANGER, 1997, p. 9-24; BANN, 1994, p. 13-25; 51-86).

\footnotetext{
2 Utiliza-se o termo "história da memória" no sentido de uma exploração arqueológica das narrativas históricas e literárias sobre a cidade e a nação, que permite a elaboração de uma genealogia do surgimento e institucionalização de formas de explicação sobre as dinâmicas das sociedades no tempo. Nesse sentido, essa empresa exploratória orienta-se pelas questões propostas por NORA (1993, p.7-28); GEARY (1996, p. 17-46); MATSUDA (1996, p. 3-17); e LOWENTHAL (1995, p. 183-259).
} 
A memória coletiva não é apenas uma conquista, mas também objeto e instrumento de disputas pelo poder. Um exemplo disso é o Projeto Memórias Reveladas (www.memoriasreveladas.gov.br), criado em 2007, para receber, gerir e divulgar a documentação sobre a violação dos direitos humanos durante a ditadura militar. Assim, seria possível discutir e reescrever a história da sociedade brasileira nesse período a partir de documentos e memórias alternativas que questionam os relatos e arquivos oficiais legados pelos governos militares. Outro exemplo é a troca das denominações de ruas, de avenidas e de logradouros públicos que homenageavam a memória dos governantes militares para nomes que celebram a luta pela redemocratização da sociedade brasileira, como no caso da Avenida Castelo Branco na entrada da cidade de Porto Alegre, que foi renomeada pela Lei Complementar Municipal no. 11.688/2014 para Avenida da Legalidade e da Democracia.

Segundo Costa (2011, p. 78), uma parte da produção contemporânea em arte vem realizando operações desconstrutivas dos mecanismos disciplinares de preservação da memória presentes na instituição de Arte - autoridade hermenêutica, os discursos eurocêntricos, as exigências de mercado, a noção de exposição, o modo de expor, o valor e a propriedade dos objetos, etc.

$\mathrm{O}$ artista contemporâneo pesquisa em arquivos de museus, em bibliotecas e de outras instituições, coleta materiais em arquivos familiares ou em feiras livres, registra em fotografia obras efêmeras, mantém seu arquivo de projetos, de processos de criação, de exposições e de crítica. Assim, trabalha constantemente sobre documentos, produzindo outros documentos como reflexão sobre seu processo de criação.

$\mathrm{O}$ artista trabalha a partir desses materiais de arquivo, dos seus próprios, dos de terceiros e dos públicos, lançando mão de mudanças de meio (materiais e dispositivos), de escala (ampliação e redução) e de intervenções (tinta, cor, montagem) para resignificá-los e gerar obras que problematizem a memória e a história. Rosangela Rennó é uma artista que trabalha com arquivos sobre as memórias e os esquecimentos sociais em suas obras desde os anos 1980.

Rosangela Rennó ${ }^{3}$ nasceu em Belo Horizonte (Minas Gerais), em 1962, graduou-se em Arquitetura pela UFMG (1986) e Artes Plásticas pela Escola Guignard (1987). Em 1989, mudou-se para o Rio de Janeiro. Em 1997, conclui o doutorado em Artes pela ECA/USP. Recebeu várias bolsas de pesquisa: Civitella Ranieri Foundation (1995), Fundação Vitae (1998) e John Simon Guggenheim Memorial Foundation (1999). Participou de muitas exposições nacionais (Bienal de São Paulo) e internacionais

3 Cf. biografia Enciclopédia Itaú Cultural.Disponível em: <http://enciclopedia.itaucultural.org.br /pessoa10376/rosangela-renno>. Acessoem : 10 nov. 2015. 
(Bienal de Veneza, Fotografia Brasileira Contemporânea em Frankfurt), além de ter sua obra em várias coleções públicas e privadas no Brasil e no exterior ${ }^{4}$.

No final da década 1980, começou a trabalhar com álbuns de família, apropriando-se de imagens e problematizando a montagem do dispositivo, a memória e o esquecimento. Temas que seriam constantemente retomados e problematizados em seus projetos posteriores que se voltaram para a memória e o esquecimento público. Em 1992, Rennó inicia o projeto "Arquivo Universal" que se desdobraria em vários trabalhos, exposições e publicações. A artista trabalha com imagens esquecidas, imagens ausentes, problematizando o desaparecimento e a amnésia social através de fotografias, de textos, de notícias de jornais. Utilizando-se de vídeo, de instalações e de materiais variados ela se apropria das imagens alheias para questionar o esquecimento social.

Para a artista, a arte é como um instrumento de ampliação da experiência. Rennó se interessa pelos usos sociais da imagem, pela produção vernacular desprovida de intenção artística, de uma espécie de margem da fotografia. Daí a escolha de trabalhar com fotos $3 \times 4$ produzidas para documentos, com fotografias de notícias de jornais e com arquivos públicos. Ela afirma trabalhar com imagens alheias, pois o que lhe importa é "problematizar os sistemas classificatórios, investigar os modos de ver e como as coisas envelhecem" ${ }^{2}$. Em A mulher que Perdeu a Memória (1988) In Oblivionem (1994) a artista já abordava o esquecimento e as potencialidades expressivas da fotografia, problematizando o estatuto público e privado das imagens, bem como as formas de ver.

Através de suas obras ela extrapola os limites dos suportes - dos dispositivos, entre eles o fotográfico - ganhando potência nessa nova relação entre a imagem e a plataforma na qual ela é apresentada. A artista utiliza em suas obras procedimentos de veladura parcial das imagens e de formas expositivas que dificultam a visualização imediata das imagens, forçando o observador a um trabalho de ver e a um esforço de interpretação daquilo que se encontra diante dele. Rennó retira as imagens de seus suportes originais (álbum, jornal, arquivo) e de seu fluxo ininterrupto de circulação no mundo provocando uma desaceleração visando a despertar seu potencial reflexivo e novos modos de ver.

\footnotetext{
${ }^{4}$ Cf. lista de exposições. Disponível em: <http://www.rosangelarenno.com.br/biografia/en>. Acesso em: 10 nov. 2015.

5 Entrevista concedida a Horacio Fernandez, Fórum Latino Americano de Fotografia de São Paulo, 22 de outubro de 2013. Disponível em:<http://www.forumfoto.org.br/rosangela-renno-e-as-imagens-que-naoexistem/>. Acesso em: 10 nov. 2015.
} 
Em Imemorial (1994), a artista problematiza a cultura do arquivo para construir um olhar político sobre a construção de Brasília. A nova capital representava a utopia de um país moderno e desenvolvido. Uma nova capital para um novo Brasil. Totalmente planejada e funcional, no meio do país, com uma nova linguagem urbanística proposta por Lúcio Costa e a arquitetônica modernista de Oscar Niemayer. Seria uma espécie de cidade-monumento para as gerações do futuro. Porém, como afirma Walter Benjamim (1987), civilização e barbárie são as duas faces da história.

A obra de Rennó consiste numa instalação de cinquenta fotografias com retratos dos trabalhadores (homens, mulheres e crianças) que construíram Brasília. As imagens foram encontradas pela artista no Arquivo Público do Distrito Federal, em malas com mais de 15 mil dossiês de ex-trabalhadores da companhia Novacap. Imagens abandonadas e relegadas ao silêncio dos arquivos, que ninguém mais queria ver, mas que precisavam ser vistas e revitalizadas para despertarem sua potência reflexiva.

Em Imemorial, ela faz referência ao episódio apagado da narrativa épica da construção de Brasília, inaugurada com grandes solenidades e festejos oficiais em 21 de abril de 1960, pelo Presidente Juscelino Kubitschek: o massacre da Pacheco Fernandes Dantas, ocorrido em 1959. Esse episódio trágico faz parte da história da construção de Brasília e expõe as condições de vida e de trabalho precárias de milhares de operários contratados pelas empresas construtoras da nova capital. Com a proximidade da data de inauguração as jornadas de trabalho se intensificaram e as turmas de trabalhadores se revezavam 24 horas no enorme canteiro de obras que era Brasília. Os operários trabalhavam em turnos de 18 horas por dia e 90 horas semanais para conseguir dobrar seus parcos salários. Eles vinham de muito longe, a maioria deles era proveniente de estados do Nordeste. Alguns vinham com as famílias, mas grande parte era composta por homens solteiros que moravam em acampamentos.

As condições de vida nos galpões das construtoras eram muito precárias. Os galpões eram feitos de madeira com teto de telhas de zinco, possuíam de 10 a 15 quartos com beliches de duas ou três camas. O sanitário era um buraco escavado no chão com uma lona servindo de porta. Os colchões eram de capim e ficavam infestados de parasitas. A falta de higiene favorecia a proliferação de pulgas, percevejos e piolhos. Os materiais de construção empregados e a concentração de gente nos galpões no clima quente do planalto central não ofereciam qualquer conforto. Além disso, as cantinas que forneciam refeições aos trabalhadores serviam por vezes comida crua ou estragada. Devido às estafantes jornadas de trabalho e as péssimas condições de vida nos acampamentos das construtoras, os operários seguidamente se revoltavam e a Guarda Especial de Brasília (GEB) era chamada a intervir. 
O massacre ocorreu em um domingo de carnaval de 1959 no acampamento da construtora Pacheco Fernandes Dantas. Existem duas versões para o ocorrido, a oficial das autoridades nos jornais e a dos operários, conhecida através de depoimentos orais a pesquisadores. Nair Heloisa Bicalho de Sousa pesquisou o massacre, escreveu um livro (1993) e vários artigos sobre o esquecimento oficial e as memórias dos trabalhadores acerca do ocorrido naquela noite de carnaval. Vale a pena fazer um pequena síntese de seu trabalho para compreender melhor a violência do Estado e o silenciamento da memória dos vencidos.

Naquele domingo de carnaval, ocorreu um conflito entre um operário da construtora e um funcionário da cantina por causa da má qualidade da comida. Dois policiais teriam comparecido ao local e foram expulsos pelos operários. A paz parecia ter retornado ao acampamento e todos foram dormir depois de uma longa jornada de trabalho. À noite, caminhões de soldados da GEB cercaram o galpão, formando duas filas e exigindo que todos os operários saíssem para a rua, sendo recebido a golpes de cassetete e pontapés. Alguns trabalhadores apavorados tentaram fugir e a polícia abriu fogo sobre eles e os barracões. As balas atravessaram as paredes de madeira e atingiram também alguns operários que dormiam. Houve vários mortos, fala-se de 20 ou de 50 vítimas. Porém, uma testemunha afirma ter visto 93 malas abandonadas no galpão da construtora no dia seguinte. Os próprios operários teriam sido obrigados a carregar os corpos dos mortos para dentro de um caminhão e limpar o barracão. Segundo o depoimento de um antigo operário, os corpos dos trabalhadores teriam sido enterrados em uma vala aberta ao pé da torre de comunicações da cidade (Sousa, 1983). Apenas três jornais noticiaram parcialmente o ocorrido naquele domingo de carnaval: Jornal do Brasil (14/02/1959), A Notícia (13/02/1959) e O Estado de São Paulo (14/02/1959).

A memória oficial reconhece apenas uma vítima. Denúncia foi encaminhada e um processo foi aberto pelo Sindicato dos Trabalhadores da Construção Civil, mas nada foi apurado pela justiça e o caso terminou arquivado. O livro de memórias do presidente Juscelino Kubitschek 50 anos em 5 (1978) nada fala sobre o caso. Da mesma forma, os arquitetos Lucio Costa e Oscar Niemayer afirmaram desconhecer o ocorrido. O presidente da NOVACAP, Ernesto Silva, minimiza o incidente e não reconhece o número de vítimas, afirmando tratar-se de um fato isolado nos três anos e meio de construção de Brasília.

Os arquivos encontrados falam de trabalhadores que se insurgiram contra as más condições de trabalho - falta de água potável, comida estragada, barracões precários, longas jornadas de trabalho e baixa remuneração - nos alojamentos improvisados, que foram construídos para serem posteriormente destruídos no local 
que seria inundado para a formação do Lago de Brasília. A Polícia da Nova Capital abriu fogo contra eles, matando dezenas de trabalhadores. Nos arquivos da NOVACAP encontrados pela artista, consta em algumas das fichas dos trabalhadores a informação: "dispensados por motivo de morte"!

O nome da exposição "Imemorial" é uma forma irônica de dialogar com os vários memoriais construídos em Brasília para celebrar a memória e as realizações dos governantes do passado. O que seria um memorial? Um lugar de culto a memória de determinados acontecimentos e sujeitos que explicariam o passado de uma nação? Um "lugar de memória" (NORA, 1993), cujo objetivo pedagógico é educar os cidadãos do presente e do futuro através de uma concepção heróica da história? Então, o que seria um Imemorial? Um lugar de desmontagem dessa concepção heróica e pedagógica do passado visando reescrever a história a contrapelo?

A obra Imemorial de Rosangela Rennó se contrapõe, especialmente, ao Memorial JK localizado no Eixo Monumental de Brasília, que celebra a memória do expresidente Juscelino Kubitschek e foi inaugurado em 1981. O memorial foi construído a partir de projeto arquitetônico de Oscar Niemayer, com obras de Athos Bulcão e uma escultura do JK de 4,5 metros de Honório Peçanha. O conjunto imponente abriga uma câmara mortuária com os restos mortais de Juscelino Kubitschek em um salão oval revestido de mármore negro com teto iluminado por luz natural, que penetra no recinto através de um vitral com a imagem de um anjo. O Memorial JK conta ainda com 3.000 livros, fotografias, roupas e objetos pessoais do ex-presidente, além de uma exposição permanente sobre sua trajetória pública e vida privada. As formas arquitetônicas, os materiais escolhidos, o tipo de iluminação, a presença da câmara mortuária e as escolhas expográficas propõem um culto à memória do ex-presidente e fundador da cidade.

Já o Museu Vivo da Memória Candanga localiza-se fora do Eixo Monumental, no antigo Hospital Juscelino Kubistchek de Oliveira (HJKO), que funcionou no Núcleo Bandeirante (antiga "Cidade Livre") até a metade dos anos 1970. Criado em 1990, com uma estrutura bem mais modesta, ele conta com acervos dos primeiros fotógrafos da cidade - Mario Moreira Fontanelle, Peter Scheir e Joaquim Paiva - e exposição permanente sobre os primeiros anos da capital. O museu também possui um auditório, uma galeria e um espaço para as "oficinas do saber fazer" de artesanato e arte popular. A distância física, dos meios materiais de expressão e de concepção entre os dois memoriais não deixa margem a dúvidas sobre o lugar de cada um desses grupos sociais - elites governantes e trabalhadores - nas disputas entre memória e esquecimento na narrativa da construção da nação. 
Nesse sentido, a obra de Rosângela Rennó é uma espécie de anti-memorial com uma proposta de reescrever a contrapelo a história da construção da cidade e da nação. Um "imemorial” no sentido benjaminiano, pois se a história é este cortejo de vencedores, em que os governantes de hoje são os herdeiros dos vencedores do passado, devemos lutar contra essa narrativa e o esquecimento dos vencidos para que eles não sejam derrotados uma segunda vez. Bertold Brechet perguntava-se em Perguntas de um operário letrado (1986):

Quem construiu Tebas, a das sete portas?

Nos livros vêem-se o nome dos reis,

Mas foram os reis que transportaram as pedras?

Babilônia, tantas vezes destruída,

Quem outras tantas a reconstruiu? Em que casas

Da Lima Dourada moravam seus obreiros?

No dia em que ficou pronta a Muralha da China para onde

Foram os seus pedreiros? A grande Roma

Está cheia de arcos de triunfo. Quem os ergueu? Sobre quem

Triunfaram os Césares? A tão cantada Bizâncio

Só tinha palácios para os seus habitantes?

A exposição é composta de cinquenta fotografias agrupadas em faixas horizontais na parede e no solo. As fotografias das mulheres e das crianças trabalhadoras são apresentadas em cores acinzentadas na parede branca As fotografias dos trabalhadores mortos são apresentadas em preto alinhadas horizontalmente no chão escuro da galeria. Chama à atenção a presença de retratos de crianças de pouca idade entre os operários da nova capital. Observa-se uma oposição entre as fotos mais claras de crianças e mulheres penduradas verticalmente na parede branca (vida) e as alinhadas no solo escuro (morte). Há espaços vazios entre as imagens, uma abertura à interpretação que solicita ao observador que os complete com outras imagens. Os vazios amplificam ausência e sensação de abandono.

A obra de Rennó resignifica estes retratos de identificação que mudam de estatuto, passando de documentos de identificação da construtora para imagens artísticas. Retratos que nos colocam diante de vestígios da existência desses sujeitos ausentes da história da nação. Uma presença-ausência que ativa a memória dessa falta. Tornam-se "provas" no tribunal da história, peças de um processo contra a violência das relações de trabalho e a impunidade das construtoras e autoridades governamentais diante do massacre da Construtora Fernandes Pacheco Dantas. Segundo Rennó (1998, p. 132):

...as fotografias foram feitas em filme gráfico, cuja superfície muito brilhante e pintada de preto por trás, se torna um espelho negro, indicativo do lugar de sobra social em que esses narcisos experimentaram o desamor coletivo por si. 
Nesse "espelho negro da história", o observador pode contemplar um rosto, quase um fantasma, mas também o seu próprio rosto (como nos daguerreótipos). Desta forma, a artista problematiza a relação entre o "eu" do observador e o "outro" desconhecido, entre o presente e o passado, entre a vida e a morte. Nós os vemos e eles no olham desse não lugar da história, nos intimando a pensar sobre a sua morte e seu o esquecimento social. Pensar sobre a fragilidade e o desaparecimento cada um de nós. Imemorial poderia referir-se a exploração desses trabalhadores, as formas de esquecimento social dos "de Baixo" e o cortejo dos vitoriosos na História.

A disposição das imagens no chão enfileiradas como lápides e a cor negra que recobre os retratos dificultam uma aproximação dessas fotografias como um espelho do real. A instalação assemelha-se a um monumento fúnebre em memória dos trabalhadores que construíram Brasília. É como se pudéssemos abrir os seus túmulos e ver novamente seus rostos vindos do passado e que nos olham no presente. A obra não oferece uma reconstituição de suas identidades ou de suas memórias, apenas as presenças espectrais desses outros que nos falam através de sua ausência (morte e esquecimento social) do que ainda resta saber sobre os que construíram a capital de um desejado país "novo e moderno". As fotografias são como imagens-fantasmas desses "outros", desconhecidos e esquecidos pela história e pela sociedade, que nos contemplam e nos desafiam a dar um significado as suas presenças-ausências.

Imemorial (1994) - Instalação para a exposição "Revendo Brasília" - 40 retratos em película ortocromática pintada e 10 retratos em fotografia em cor em papel resinado sobre bandejas de ferro e parafusos. Título Imemorial na parede em letras de metal pintado. $60 \times 40 \times 2 \mathrm{~cm}$ (cada moldura de ferro) - Coleção de Marcos Vinícius Vilaça.

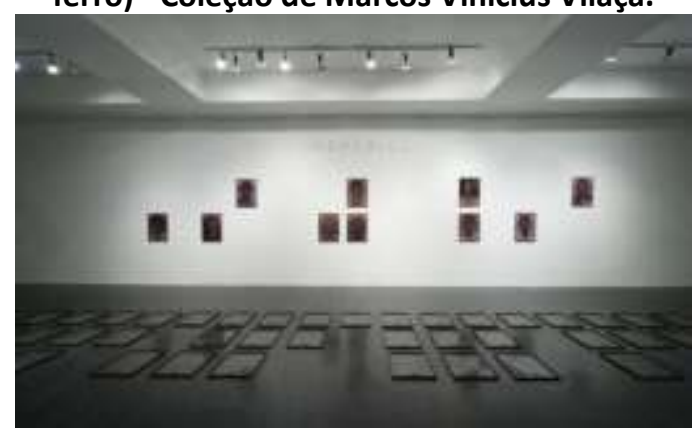

Fonte: Disponível em: <http://www.rosangelarenno.com.br/obras/view/19/1>. Acesso: 9 nov. 2015.
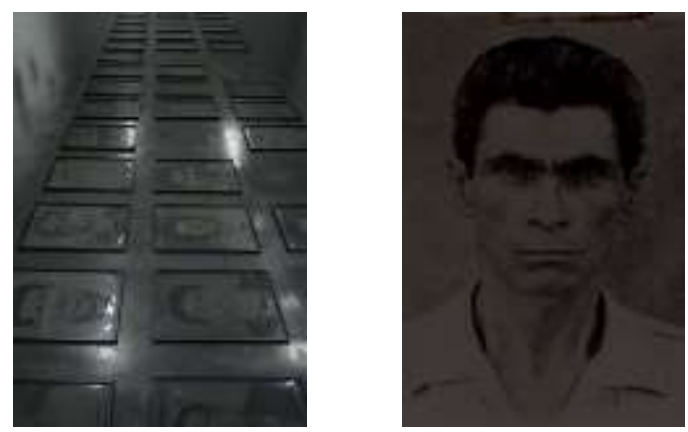

Fonte: (site da artista): http://www.rosangelarenno.com.br/obras/view/19/1. Acesso: 9 nov. 2015. 
A obra problematiza a visibilidade social dos trabalhadores e a construção social de uma identidade moderna no Brasil. Como o moderno pode se constituir através de formas de organização do trabalho e de dominação políticas arcaicas, que remontam a herança do passado escravocrata e ao genocídio indígena do período colonial? Diante dessas imagens estamos diante do tempo, como diria Didi-Huberman (2008). De uma realidade incomoda que gostaríamos de esquecer e que retorna a superfície através desses retratos de trabalhadores mortos. Fantasmas que nos vêm do passado, cujos retratos nos contemplam!

Essas imagens ampliadas, dispostas lado a lado no chão, retratos enegrecidos de trabalhadores e trabalhadoras permitem problematizar a narrativa épica sobre a construção da cidade e o projeto republicano de nação, que desejava libertar o país dos dilemas do passado escravista e autoritário. Essas imagens invertem a nossa percepção do tempo e nos fazem pensar no tráfico escravista, nas vagas de imigrantes do passado aliciados pelos donos das companhias de vapor europeias, mas também no nosso presente. Fotografias de homens e mulheres ausentes que nos recordam as dos cidadãos assassinados pela ditadura militar e dos desaparecidos, que continuam insepultos.

Convocam-nos também a pensar nas condições de trabalho nas confecções instaladas nos porões do bairro Bom Retiro, em São Paulo, onde imigrantes trazidos por rotas ilegais trabalham de forma quase escrava; na condição precária dos haitianos que chegam ao Norte do país em busca de uma vida melhor; bem como nos agricultores sem-terra e nas trabalhadoras e trabalhadores urbanos em suas longas e penosas jornadas diárias de labuta e de deslocamento desde a periferia das grandes metrópoles brasileiras. Pensar sobre a vida nas margens da cidade e da sociedade.

A arte nos desafia a repensar a história e, sobretudo, desmontar as narrativas hegemônicas e a problematizar os esquecimentos dos arquivos públicos, bem como questionar nossa identidade nacional fraturada e os futuros-passados derrotados de nossos projetos sociais coletivos. Os diálogos entre História Social, História da Arte e Cultura Visual colocam a possibilidade de elaborar novos problemas e de propor novas interpretações para novas-velhas questões sobre a memória e a amnésia sociais de nossa jovem nação.

\section{REFERÊNCIAS:}

BANN, S. As invenções da história: ensaios sobre a representação do passado. São Paulo:

UNESP, 1994. 
BENJAMIN, Walter. Doze teses sobre a história. In: . Obras escolhidas: vol. 1: magia e técnica, arte e política: ensaios sobre literatura e história da cultura. São Paulo: Brasiliense, 1987. p. 222-232.

BRECHT, Bertolt. Poemas, 1913-1956. São Paulo: Brasiliense, 1986.

COSTA, Luiz Cláudio da. O artista an-arquivista: os dispositivos de coleção na arte contemporânea. In: Revista Porto Arte: Porto Alegre, v. 18, n. 30, maio 2011, p. 77-89.

DIDI-HUBERMAN, Georges. Ante el tiempo. Buenos Aires: Adriana Hidalgo, 2008.

ENCICLOPÉDIA Itaú Cultural. Disponível em: <http://enciclopedia.itaucultural.org.br>.

GEARY, P. La mémoire et l’oubli à la fin du premier millénaire. Paris: Aubier, 1996.

HALBWACHS, M. A memória coletiva. São Paulo: Vértice, 1990.

HARTOG, F. Tempo e história: como escrever a história da França hoje? In: História Social, UNICAMP, n. 3, 1996, p. 127-154.

HOBSBWAN, E.; RANGER, T. (orgs.) A Invenção das tradições. São Paulo: Paz \& Terra, 1997.

LE GOFF, Jacques. História e memória. Campinas: Ed. UNICAMP, 1994.

LOWENTHAL, D. The past is a foreing country. Cambridge: Cambridge University Press, 1995.

LOWENTHAL, D. Como conhecemos o passado. In: "Trabalhos da Memória", Projeto História, São Paulo, n. 17, nov. 1998, p. 63-201.

MATSUDA, M. K. The memory of the modern. New York: Oxford University Press, 1996, p. 3-17

MIRANDA, W. Cenas Urbanas. In: BIGNOTTO, Newton (org). Pensar a República. Belo Horizonte: UFMG, 2000.

NORA, P. Entre memória e história: a problemática dos lugares. In: Projeto História, São Paulo, n. 10 , dez. 1993, p. 7-28.

RENNÓ, Rosangela. Rosangela Rennó. São Paulo: Ed. da Universidade, 1998.

ROUSSO, H. A memória não é mais o que era. In: FERREIRA, M. M.; AMADO, J. (orgs.). Usos e abusos da história oral. Rio de Janeiro: Ed. da Fundação Getúlio Vargas, 1996, p. 94-95.

SOUSA, Nair Heloisa Bicalho de. Construtores de Brasília. Petrópolis: Vozes, 1983. 